\title{
Mineração
}

\section{Quantificação de riscos na avaliação estéril/minério}

\author{
Roger Luis Stangler \\ Geólogo, Doutorando do PPGEM, UFRGS \\ E-mail:roger@ufrgs.br
}

João Felipe C. L. Costa

Eng. de Minas, Prof. Dr. do DEMIN, UFRGS

E-mail: jfelipe@ufrgs.br

Jair Carlos Koppe

Eng. de Minas e Geólogo, Prof. Dr. do DEMIN, UFRGS

E-mail: jkoppe@ufrgs.br

\section{Resumo}

A razão estéril/minério é um importante fator na exequiibilidade de minas a céu aberto. Precisos modelos digitais de elevação topográfica e outras superfícies de interpolação bem delineadas são imprescindíveis nesse tipo de análise. Esse artigo apresenta uma combinação de krigagem ordinária, para construir um modelo tridimensional de cobertura estéril, e de simulações estocásticas condicionais, para visualização de múltiplos cenários de tonelagem do depósito. O primeiro método permite obter os mais acurados modelos. $\mathrm{O}$ segundo avalia a incerteza na estimativa de recursos minerais. A integração do modelo único do volume de cobertura estéril com os múltiplos modelos para a tonelagem de minério do depósito torna possível avaliar o âmbito de oscilação de razões estérilminério equiprovavelmente esperadas. A metodologia é ilustrada por um estudo de caso em um depósito de argila cerâmica no sul do Brasil.

Palavras-chave: razão estéril-minério, risco, métodos geoestatísticos.

\begin{abstract}
Stripping ratio plays a major role in the profitability of open cast mines. Precise digital elevation models and other interpolation surfaces used for overburden volume definition are required. This paper uses ordinary kriging to build a $3 D$ overburden model and conditional simulations to model multiple scenarios for the deposit tonnage. The former permits to obtain the best interpolated models. The second provides the tools to assess the uncertainty in mineral resources. Combining overburden volume model and multiple models for the deposit tonnage makes possible to evaluate the range of equally probable expected stripping ratios. The methodology is demonstrated in a clay deposit in Southern Brazil.
\end{abstract}

Keywords: stripping ratio, risk, geostatistical methods.

Artigo recebido em 15/04/2002 e aprovado em 12/08/2002 


\section{Introdução}

Minerais industriais usados na fabricação de azulejos e pisos cerâmicos são muito importantes na economia do sul do Estado de Santa Carina. A argila é um ingrediente básico nos processos cerâmicos industriais.

Argilo-minerais usados na indústria cerâmica normalmente possuem baixo valor unitário. A combinação de custos de produção e de valor de mercado restringe distâncias de transporte minasfábricas, valores máximos de royalties e máxima razão estéril/minério. Além desses fatores econômicos, parâmetros geológicos e de engenharia devem ser acrescentados ao modelo para procedimentos de planejamento mineiro.

Durante a seleção de depósitos potenciais a serem explotados, o custo de remoção do estéril de cobertura representa um importante fator. A incerteza associada com estimativas de razões estéril/minério depende de ambos os riscos de estimativa associados com os recursos totais de argila e do volume de cobertura estéril. Depósitos com alta variabilidade podem apresentar riscos que afetam sua economicidade mineira.

Estimativas de recursos/reservas minerais associadas à análise da incerteza relacionada podem ser realizadas via simulações condicionais (Costa, 1997, Dimitrakopoulos, 1998, Rossi \& Alvarado, 1998, Thwaites, 1998, Rossi, 1999, Stangler et al., 2001, Stangler, 2001). Aplicações geoestatísticas no campo da topografia são encontradas em várias publicações (Krige \& Rendu, 1975, Olea, 1974, Clarke, 1986, Gilbert, 1989, Herzfeld et al., 1993, Luís et al., 1994, Oliveira et al., 1995, Schmitt \& Bisquay, 2000). O volume da cobertura estéril é normalmente obtido calculando-se o volume entre duas superfícies: a superfície original do terreno e o topo da camada do minério, no caso a argila cerâmica.

Os riscos, i.e., a incerteza associada com a estimativa de volumes e suas conseqüências para um projeto mineiro, requerem um novo tipo de abordagem a ser avaliada. Esse artigo propõe uma abordagem geoestatística usando kriga- gem e simulação estocástica. O primeiro método é usado para modelamento de volume de cobertura estéril; o segundo é aplicado para avaliar a espessura da camada e a variabilidade da tonelagem da argila. A metodologia proposta é ilustrada através de um estudo de caso.

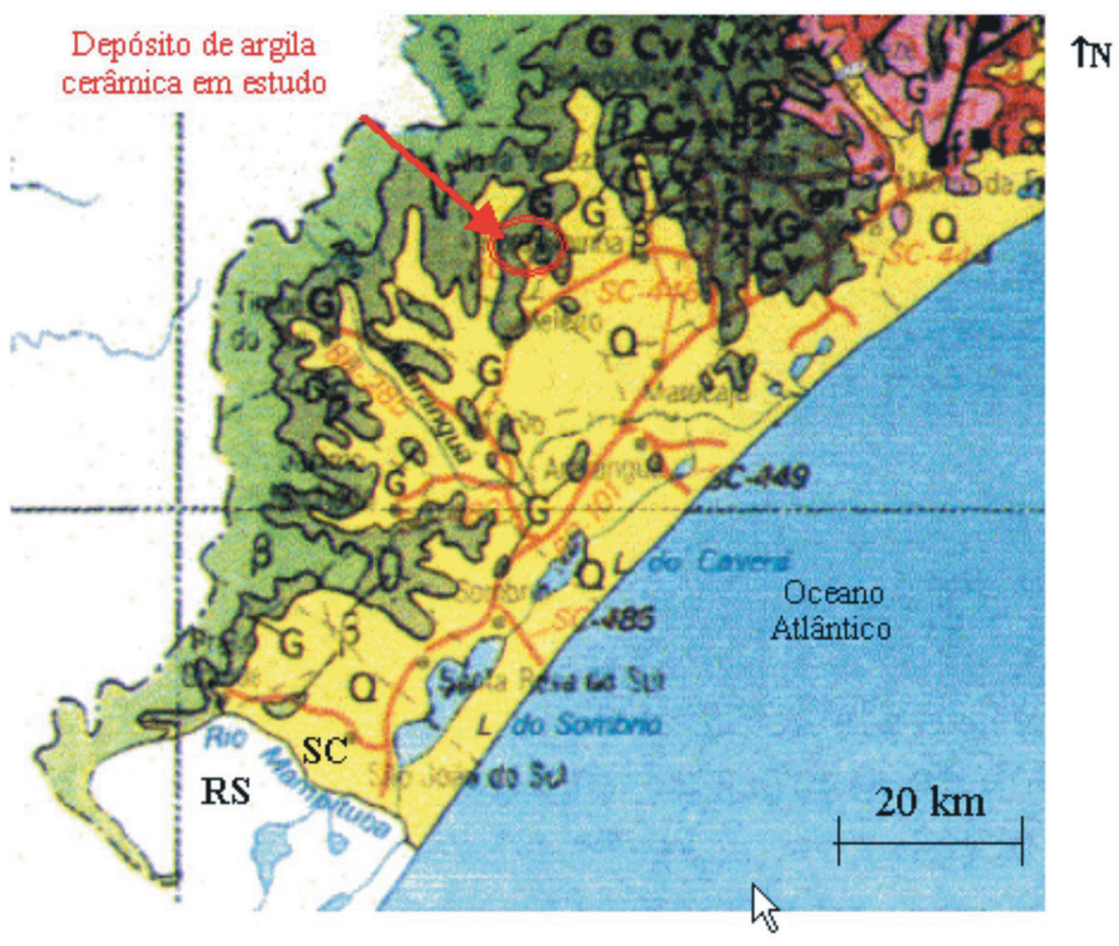

\section{LEGENDA}

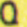

Cobertura Sedimentar Quaternária

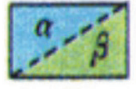

Rochas Efusivas (Formação Serra Gerał)

$\beta$ - Sequência.Basica

$\alpha$ - Sequência Ácida

\section{Cobertura Sedimentar Gonduânica}

\section{Vs Cobertura Vulcano-Sedimentar Eo-Paleozóica}

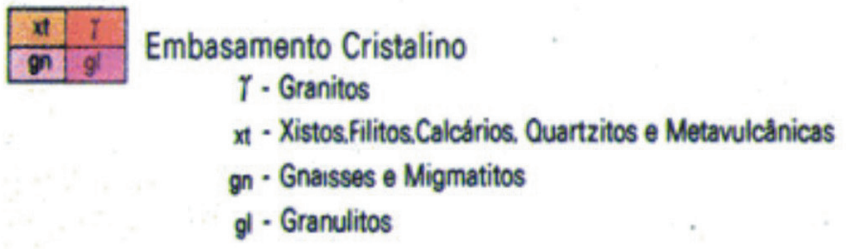

Figura 1 - Geologia regional da área de estudo (adaptada do Atlas de Santa Catarina, SEPLAN/SC, 1986). 
Essa região encontra-se encravada numa transição de unidades geológicas regionais, contato entre domínios fragmentários da seqüência sedimentar paleozóica/mesozóica da bacia do Paraná, a WNW, e uma larga planície costeira quaternária, a E-SE (Figura 1), constituída nos arredores da área por depósitos de leques aluviais e sedimentos fluviais recentes da bacia do Rio Mãe Luzia. Tais sedimentos são, na maior parte, compostos por argilas, uma vez que as rochas sedimentares tardi-paleozóicas ocorrentes nas colinas e morros adjacentes, principal fonte da sedimentação quaternária, são também constituídas principalmente por argilo-minerais.

As rochas gonduânicas pertencem à parte superior da coluna estratigráfica da bacia do Paraná, Grupo Passa Dois, Formações Serra Alta e Rio do Rasto (a Formação Teresina, intermediária entre essas duas, não foi individualizada na região). São recobertas por arenitos mesozóicos eólico-desérticos da Formação Botucatu, por sua vez encimados por centenas de metros de espessura de rochas efusivas (principalmente basaltos) da Formação Serra Geral, completando a seqüência (Figura 2). Descontinuidades laterais são freqüentemente observadas nas formações gonduânicas e sedimentos quaternários. Maiores detalhes da geologia e estratigrafia regional podem ser encontrados em Bortoluzzi et al. (1987).

A pequena área (em torno de $60 \mathrm{ha}$ ) efetivamente pesquisada encontra-se locada na Figura 2. De fato, na área propriamente dita e subjacências, são encontrados pequenos leques e planícies aluviais e secundariamente depósitos coluviais, na maior parte compostos por argilas.

A Formação Serra Geral, topo da sequiência, por apresentar litologias comparativamente mais resistentes à erosão, se destaca no topo dos morros, segurando a topografia. No outro extremo de idade geológica, os recentes sedimentos aluviais inconsolidados ocupam planícies truncadas pelas encostas dos morros. A Formação Serra Alta, composta de rochas pelíticas, ocupa o sopé dos morros, juntamente com a Formação Rio do Rasto sobreposta, composta em sua parte mais basal também de rochas predominantemente argilosas e onde ocorre uma quebra de relevo, e constitui a fonte da sedimentação do vale plano $\operatorname{logo}$ a N de São Bonifácio, onde se encontra a área pesquisada.
A argila ocorrente na planície quaternária, onde se insere a área sondada, resulta do transporte sedimentar oriundo das rochas sedimentares paleozóicas adjacentes, por si já predominantemente argilosas.

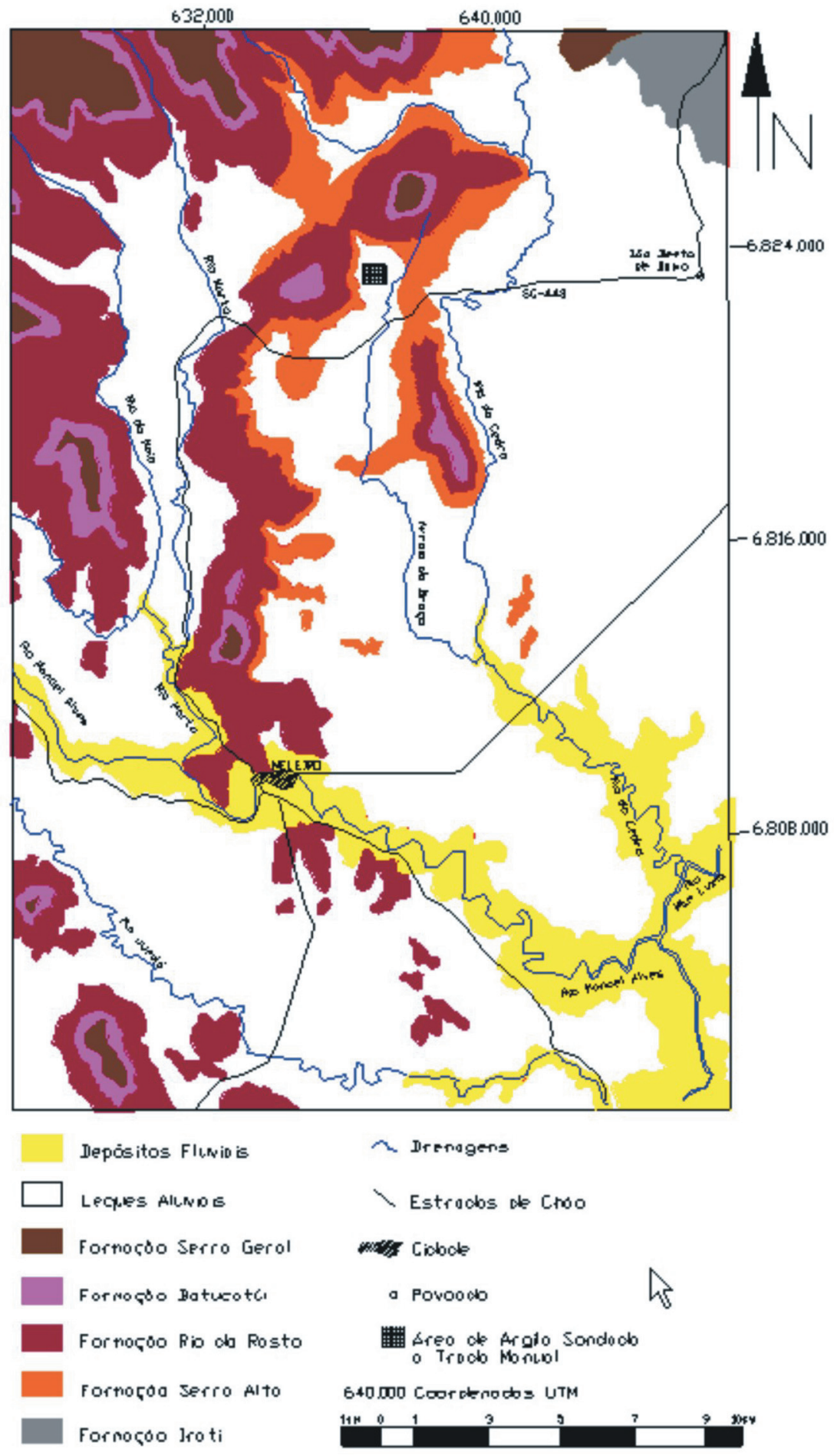

Figura 2 - Contexto geológico regional da área em estudo (mapa-base: Carta Geológica de Turvo, CPRM, 1986, escala original 1:100.000, Projeto Borda Leste da Bacia do Paraná). 
Trabalhos de mapeamento geológico/geomorfológico, conjugados a levantamento topográfico de detalhe, e o exame de tendências da distribuição espacial de parâmetros cerâmicos, obtidos em testes de laboratório, a partir de amostras de trado manual, ajudaram no delineamento de dois subdomínios geológicos: planície e tálus.

O subdomínio planície consiste de um sistema de leque aluvial formando uma planície de inundação, associado à drenagem principal NW-SE no local. Tal planície é parcialmente coberta por um depósito de tálus na porção $\mathrm{N}$ da área, compreendendo o segundo subdomínio identificado, denominado simplesmente tálus. O depósito de tálus foi formado por transporte de sedimentos grosseiros a finos, mal selecionados, a partir da encosta íngreme situada a $\mathrm{N}$ da área.

As condições geológicas locais indicam, portanto, um ambiente sedimentar compreendendo um sistema de leque aluvial, coberto parcialmente por sedimentação coluvial (tálus). A distribuição dos furos de trado manual nos dois subdomínios é apresentada na Figura 3.

A coalescência de diferentes fontes de sedimentos de leques é comum, como no caso presente, na planície do leque principal com o tálus e seus canais secundários. A interdigitação é igualmente comum. Segundo Reading (1986), a coalescência lateral é especialmente frequiente em relevos associados com falhas ativas. No depósito em estudo, existe uma transição/interdigitação entre a parte mais distal do leque, ligado à drenagem principal à W (domínio planície), e a porção mais distal do tálus. A Figura 4 ilustra esquematicamente a geometria do depósito em seus diferentes subdomínios. Note a presença de lentes de limonita, no tálus, e a ocorrência da argila aluvial sotoposta ao depósito de tálus propriamente dito, ainda nesse subdomínio.

Os dois subdomínios geológicos, planície e tálus, foram usados para definir os dois correspondentes subdomínios geoestatísticos e, como tal, serão tratados individualmente daqui por diante. A Figura 5 mostra o visível contraste geomorfológico que existe entre os dois domínios.

A argila aluvial ocorrente na planície é predominantemente quartzo-caulinítica. O substrato rochoso a essa argila compreende um follhelho preto e físsil da Formação Serra Alta. A Figura 6 mostra um corte vertical de uma pequena extração experimental de argila aproximadamente no centro da área pesquisada, na transição entre os limites do tálus e da planície. Pode-se observar a contami-

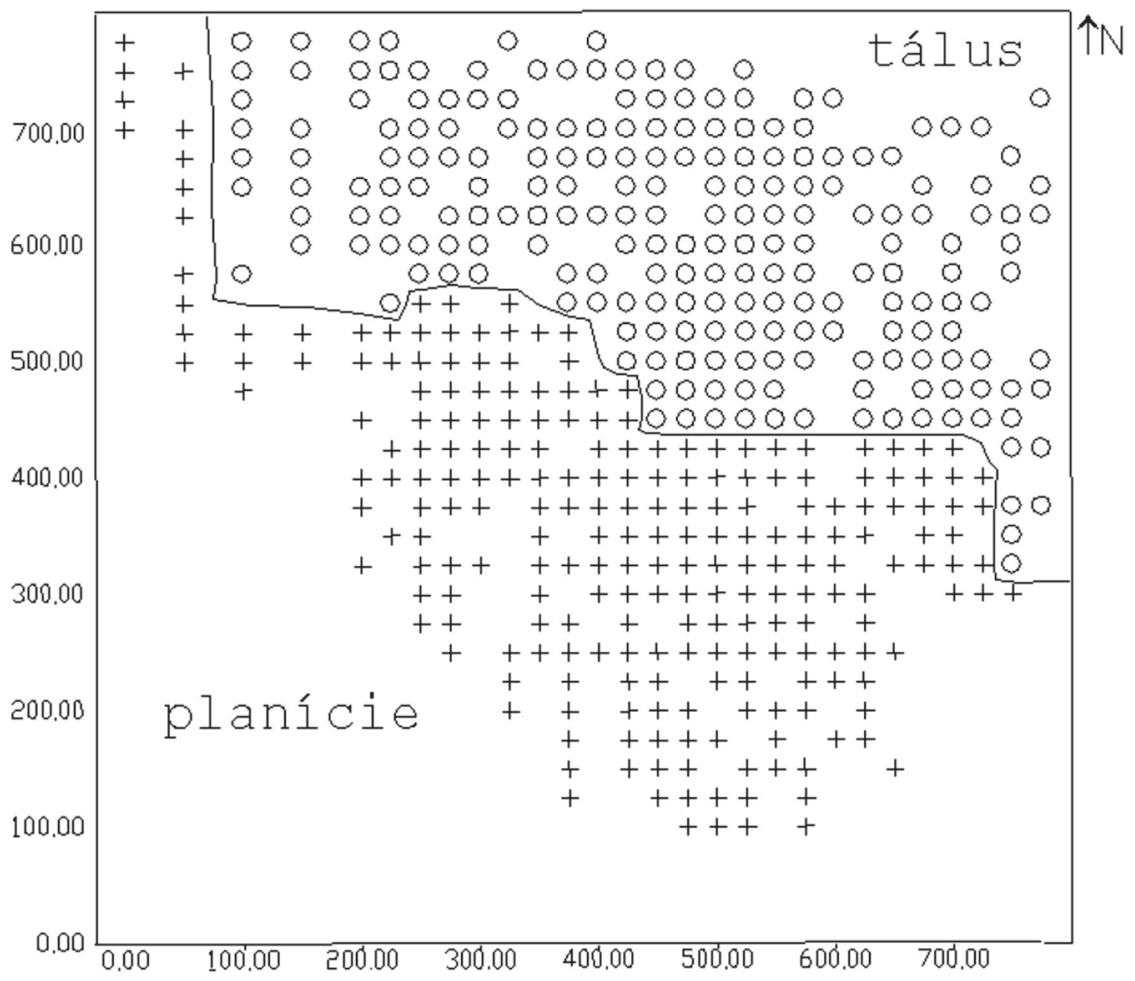

Figura 3 - Locação dos furos de trado manual (círculos e cruzes) em malha 25x25m. A linha contínua separa os dois domínios geológicos através de um contato geológico transicional.

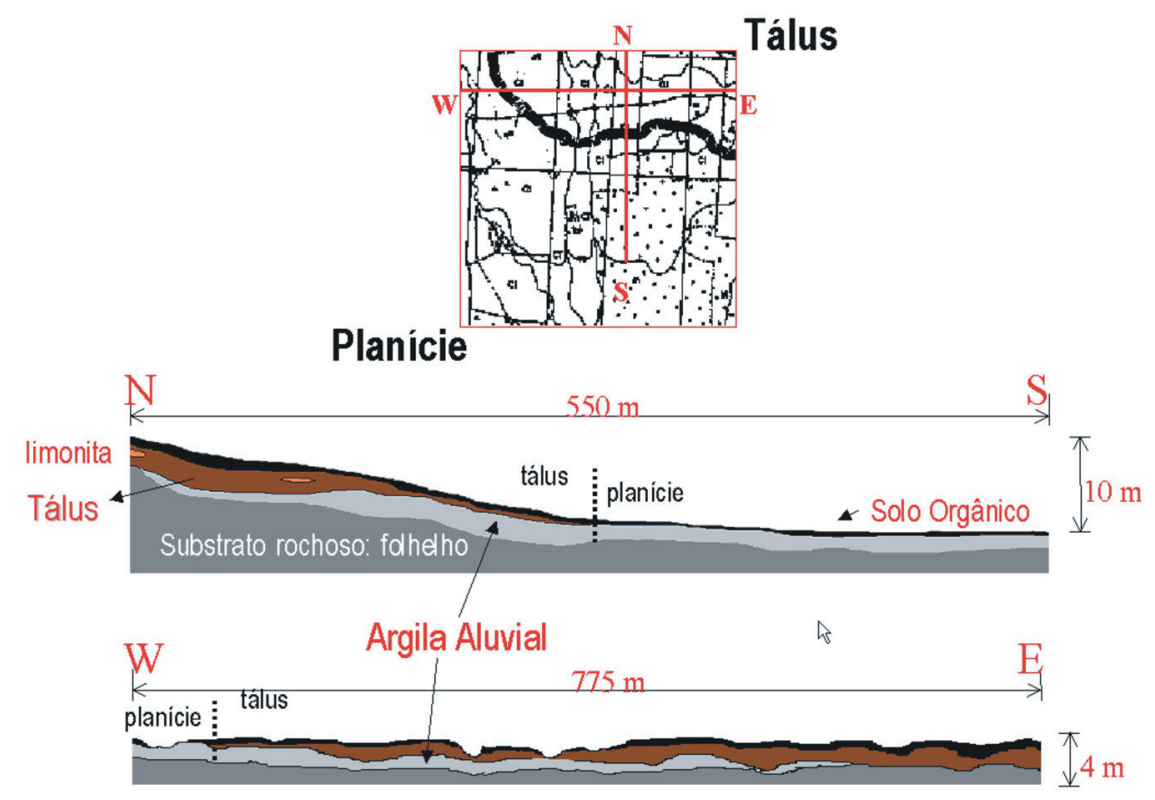

Figura 4 - Seções verticais esquemáticas cortando os dois subdomínios geológicos da área pesquisada. 


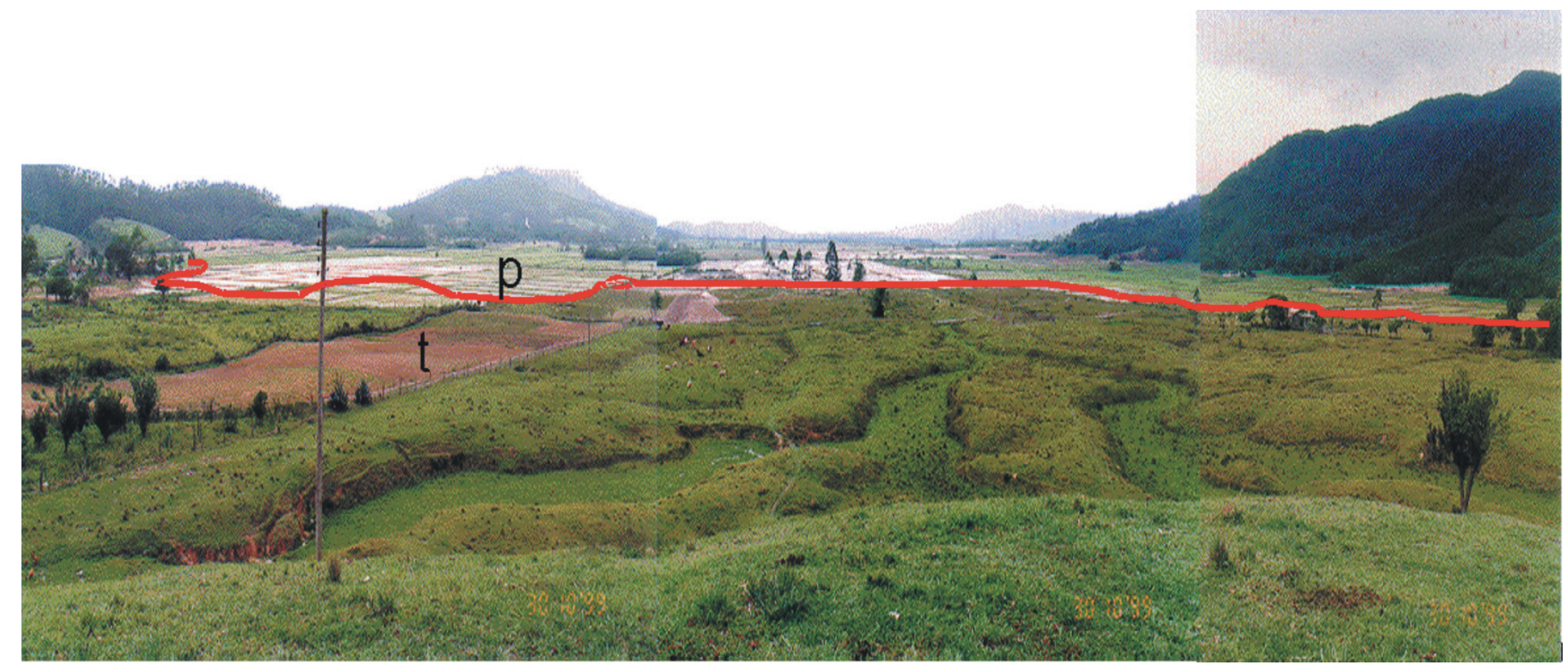

Figura 5 - Vista da área de $\mathrm{N}$ para S, com limites aproximados dos dois domínios geológicos (« $\mathrm{t} »=$ tálus; « $\mathrm{p} »=$ planície.

nação por vezes ocorrente na argila, correspondente a incrustações de limonita. Um maior detalhamento dos aspectos geológicos locais pode ser encontrado em Stangler (2001). Esse trabalho se focará na análise da razão estéril-minério do subdomínio mais ao sul, planície, considerado de maior potencial para aproveitamento cerâmico.

\section{Levantamento topográfico}

Dados de levantamento topográfico plani-altimétrico foram usados na construção do mapa topográfico via krigagem ordinária, resultando em pontos interpolados dispostos numa malha regular 10x10m. As Figuras 7 e 8 apresentam, respectivamente, os variogramas e o mapa de isocontornos obtido para elevação. Note que o mapa cobre a área sondada com furos de trado, tendo sido usado com auxílio para definir os dois domínios mencionados no item anterior. Os valores de elevação topográfica partem de uma referência de nível local, arbitrária, sem vinculação com o nível do mar.

\section{Banco de dados - subdomínio planície}

O banco de dados global (planície + tálus) compreende 452 furos de trado manual (diâmetro de 25 mm). As amos-

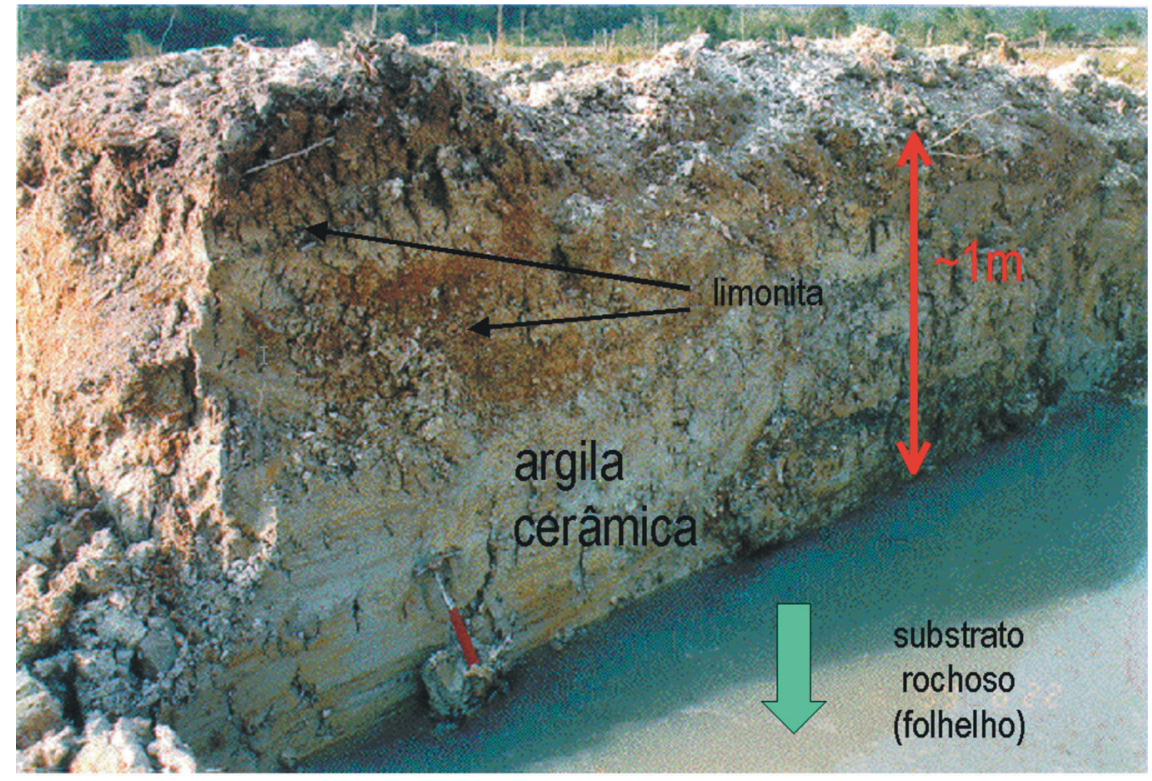

Figura 6 - Corte aberto para extração experimental de argila aproximadamente no centro da área pesquisada.

tras foram coletadas numa malha regular incompleta de $25 \times 25 \mathrm{~m}$, cobrindo uma área de 775x775 m (Figura 6). O subdomínio "planície" aqui avaliado compreende 231 furos, com uma amostra/furo.

Esses furos foram descritos e usados para definir espessuras do leito de argila de interesse e de seu capeamento estéril. A Figura 9 mostra o histograma para espessura de argila após se aplicar o procedimento de desagrupamento (Isaaks \& Srivastava, 1989, Cap. 10, Goovaerts, 1997, p.77-82).

\section{Variografia}

A análise estrutural foi realizada através do cálculo e plotagem de variogramas experimentais, seguido do ajuste de modelos variográficos. Esses modelos foram subseqüentemente usados para krigagem ordinária e simulação. Os modelos finais obtidos são apresentados nas Figuras 10 e 11.

A espessura do leito de argila exibe um maior eixo de anisotropia segundo N10W (anisotropia geométrica). Similarmente aos variogramas de elevação do 

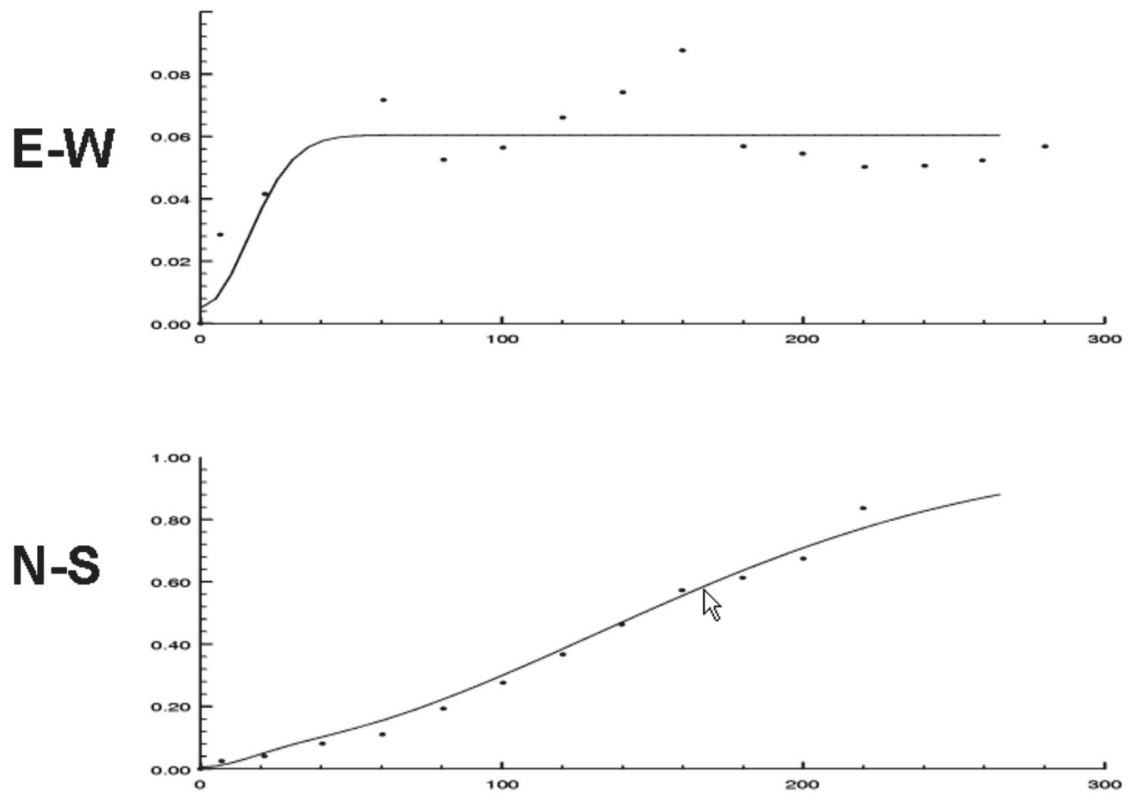

Figura 7 - Variogramas modelados para os dados de elevação: direção de maior continuidade, acima, e direção de menor continuidade, abaixo. Note a diferença de escala no eixo vertical (função semivariograma); distância em metros.

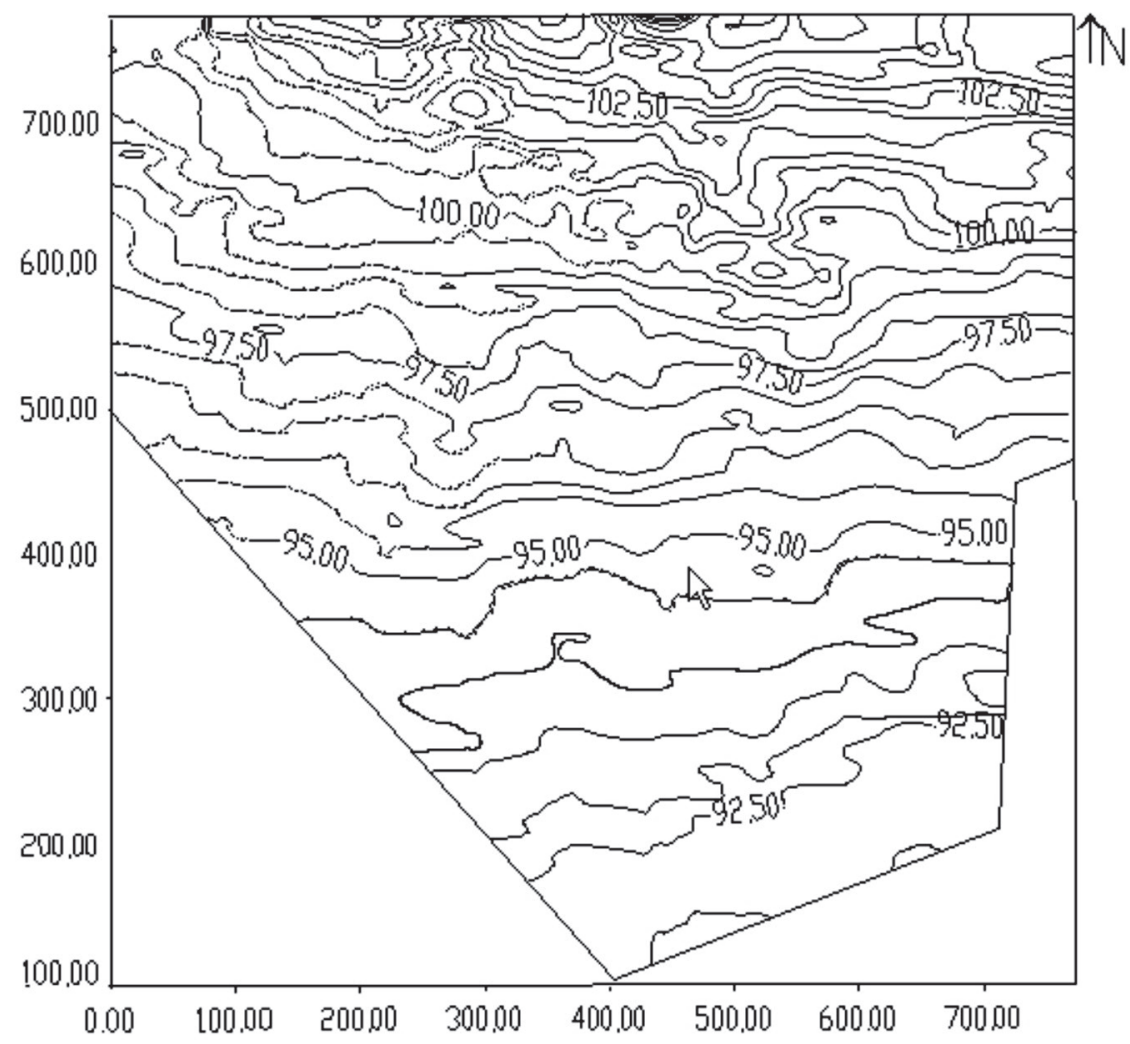

Figura 8 - Elevação topográfica para a área em estudo (linhas a cada 0,5 m). terreno, o variograma do topo da elevação do leito apresenta anisotropia, tanto zonal, como geométrica. Segundo E-W (para elevação topográfica) ou próximo a E-W (para o topo da elevação do leito de argila), as duas variáveis mostram uma grande continuidade e uma menor variância ( illl). Na direção N-S um forte drift é observado (note as diferenças nas escalas verticais das Figuras 7 e 10. A restrição de dados usados na krigagem a uma elipse de busca de curto alcance (no caso presente, $<100 \mathrm{~m}$ ), minimiza as possíveis indesejáveis consequiências que o drift pode causar às estimações (de acordo com discussões em Rossi, 1988, e Journel \& Rossi, 1989).

\section{Simulação para espessura de argila}

No intuito de avaliar a variabilidade das reservas e conseqüentemente flutuações na razão estéril/minério, o conhecimento da variabilidade da espessura de argila é imprescindível. Simulações estocásticas condicionais geradas pelo algoritmo de simulação seqüencial gaussiana (ssG) provêem as ferramentas para esse propósito (Isaaks, 1990). Stangler (2001) apresenta uma aplicação da ssG para predizer flutuações em reservas recuperáveis para o mesmo depósito.

Múltiplas simulações obtidas para espessura de argila foram ordenadas pela espessura média de argila. Os cenários otimistas (melhor), mediano e pessimista (pior) foram selecionados para uso posterior. O critério para ranking foi baseado na tonelagem total de argila, i.e., o cenário otimista é aquele representando o modelo que leva às maiores reservas. A Figura 12 mostra as três simulações selecionadas. Elas mostram características em comum, entretanto variações locais menores entre os mapas podem ser observadas.

\section{Estimação do volume do estéril de cobertura}

Diversos métodos são comumente empregados para estimar o volume de 


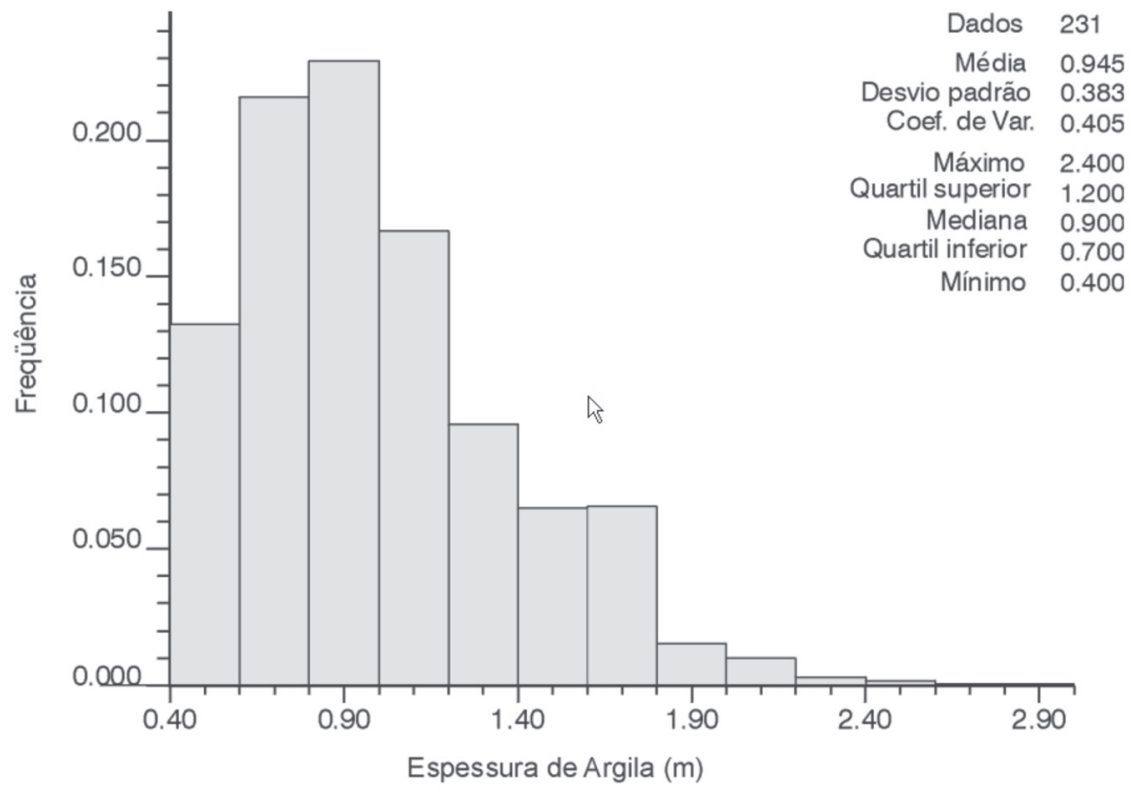

Figura 9 - Distribuição amostral desagrupada para espessura do leito de argila.

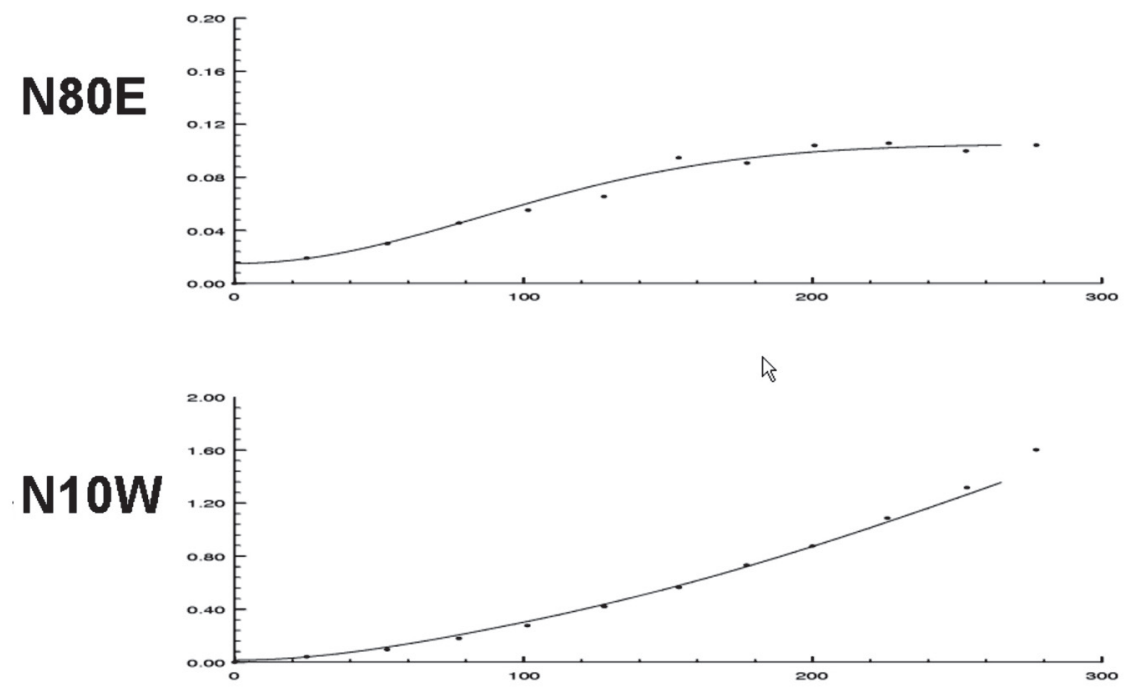

Figura 10 - Modelo variográfico para elevação do topo do leito de argila (linhas contínuas): direção de maior continuidade, acima, e direção de menor continuidade, abaixo. Distância em metros. Os pontos representam os variogramas experimentais.

estéril de cobertura (Annels, 1991, Oliveira et al. 1995). No presente estudo, o volume foi definido primeiramente modelando suas superfícies superior e inferior e, então, calculado o volume interno entre essas duas superfícies. As três etapas computacionais necessárias são explicadas a seguir.

Usando o variograma previamente apresentado (Figura 7), um modelo de elevação topográfica para a área como um todo foi obtido através de krigagem ordinária pontual (Figura 8). Dessa malha estimada, foram obtidas curvas de nível a cada $0,5 \mathrm{~m}$. Mudanças no gradiente de inclinação topográfica ajudaram na definição dos domínios geológicos.

Os mapas de contorno de elevação topográfica foram, então, truncados pelo envelope delimitando os depósitos de argila no domínio da planície, construindo, assim, o modelo digital topográfico
(Figura 13). Similarmente à superfície topográfica, a superfície de topo do leito de argila foi estimada usando krigagem ordinária, num modelo de blocos $25 \times 25 \mathrm{~m}$. O mapa de isocontornos obtido pode ser visto na Figura 14. Note as fortes similaridades entre as duas superfícies, a topografia original e o topo do leito argiloso.

$\mathrm{O}$ volume da cobertura estéril foi obtido diretamente calculando o volume definido no interior das duas superfícies estimadas por krigagem ordinária: (i) superfície do terreno; (ii) superfície de topo do leito de argila. $\mathrm{O}$ volume é apresentado na Tabela 1.

\section{Discussão}

Nas seções anteriores foram apresentados diferentes cenários igualmente prováveis para o modelo de espessura do leito argiloso, bem como um procedimento de utilização de krigagem ordinária para avaliação do volume de cobertura. Combinando os modelos simulados e o volume krigado, é possível avaliar flutuações nos valores de recursos minerais cubados e relações estéril-minério (Tabela 1).

Para o estudo de caso em análise, as tonelagens de recursos podem ter um máximo de 3,1\% acima do valor mediano obtido e um mínimo de 2,6\% abaixo. Em termos de razão estéril/minério, as flutuações máximas esperadas em torno do valor mediano são de 3\%, tanto acima, quanto abaixo. Essas baixas flutuações esperadas certamente não irão impactar a exeqüibilidade da operação mineira, o que pode não ser o caso em um outro tipo de depósito.

\section{Conclusões}

Métodos geoestatísticos consagrados como krigagem ordinária provaram ser eficientes na geração de modelos digitais de elevação confiáveis. Anisotropias zonais e drifts, freqüentemente presentes em aplicações topográficas, podem ser apropriadamente tratados, se os dados são densamente coletados. A identificação de cenários extremos e medianos para recursos globais e razão es- 

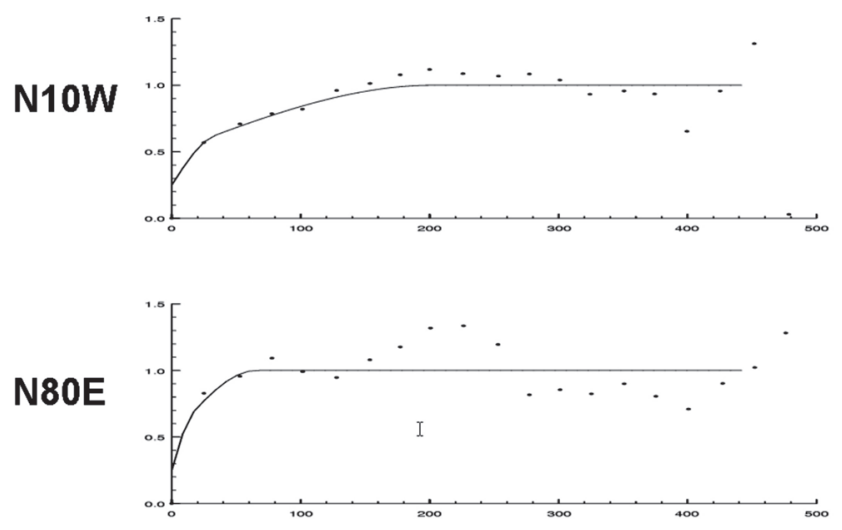

Figura 11 - Modelo variográfico para espessura do leito de argila (linhas contínuas): direção de maior continuidade, acima, e direção de menor continuidade, abaixo. Distância em metros. Os pontos representam os variogramas experimentais.

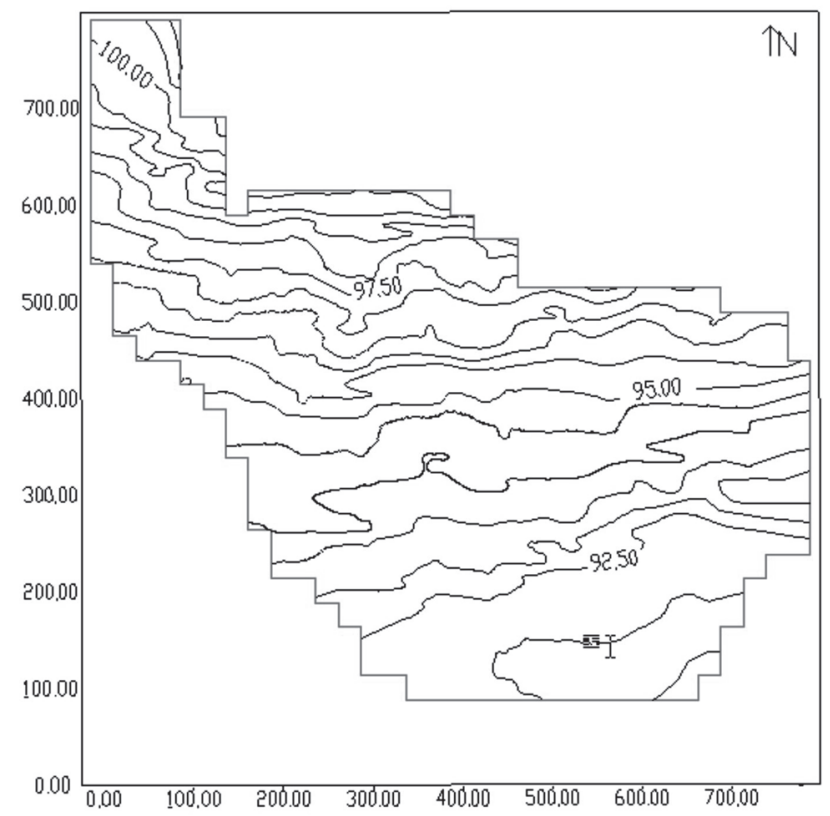

Figura 13 - Modelo digital de elevação no interior dos limites do depósito de argila (eqüidistância das curvas de nível: 0,5 m).

Tabela 1 - Sumário de recursos globais.

\begin{tabular}{|c|c|c|c|c|}
\hline $\begin{array}{c}\text { Simulações ordenadas } \\
\text { (espessura média) }\end{array}$ & $\begin{array}{c}\text { Espessura média de } \\
\text { argila }(\mathrm{m})\end{array}$ & $\begin{array}{l}\text { Recursos de } \\
\text { argila }\left(m^{3} \text { e }^{\star}\right)\end{array}$ & $\begin{array}{c}\text { Volume de cobertura } \\
\text { estéril }\left(\mathrm{m}^{3}\right)\end{array}$ & $\begin{array}{c}\text { Razão estéril/minério } \\
\left(\mathrm{m}^{3} / \mathrm{t}\right)\end{array}$ \\
\hline Maior & 0,961 & $\begin{array}{c}299.708 \mathrm{~m}^{3} \\
599.416 \mathrm{t} \\
\end{array}$ & 96.100 & 0,160 \\
\hline Mediana & 0,932 & $\begin{array}{r}290.722 \mathrm{~m}^{3} \\
581.444 \mathrm{t} \\
\end{array}$ & 96.100 & 0,165 \\
\hline Menor & 0,908 & $\begin{array}{c}283.057 \mathrm{~m}^{3} \\
566.114 \mathrm{t}\end{array}$ & 96.100 & 0,170 \\
\hline
\end{tabular}
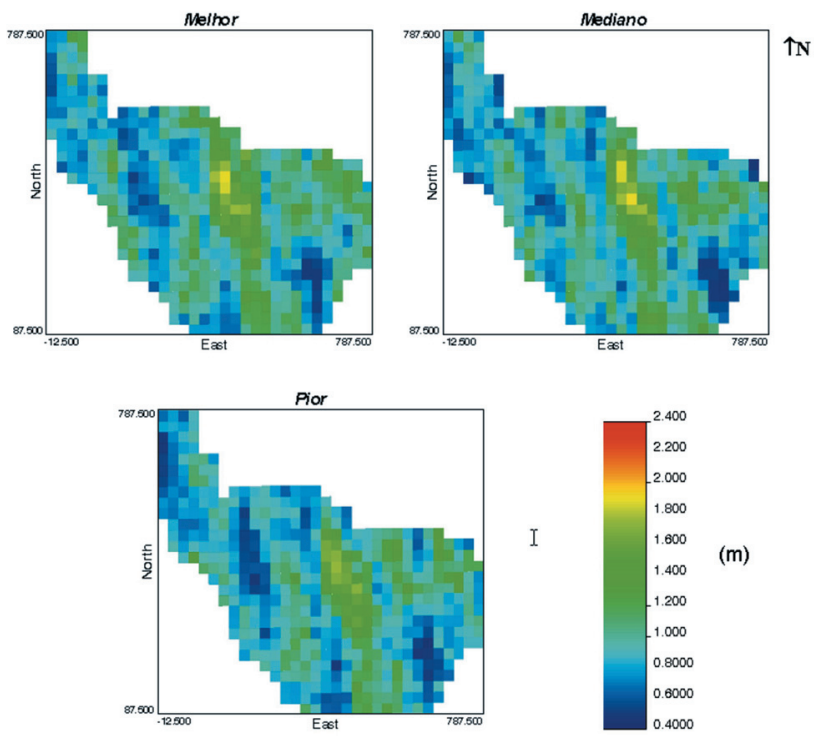

Figura 12 - Cenários extremos (melhor e pior) e mediano para espessura da camada de argila. Os mapas representam os modelos estimados para a espessura do leito de argila no suporte de blocos 25x25m (três realizações de 50 ).

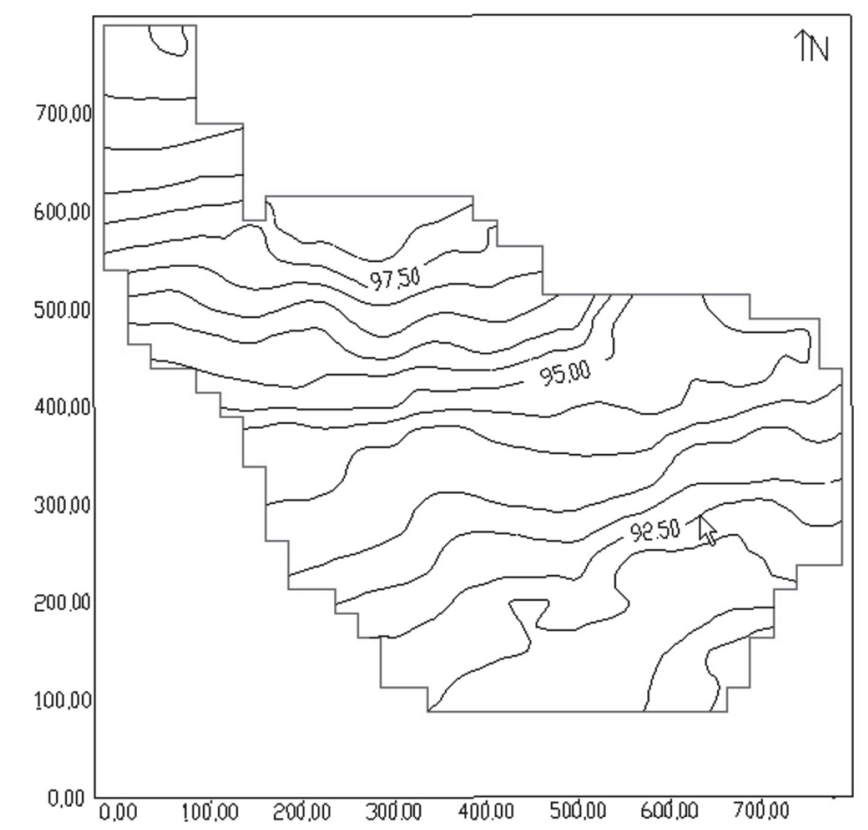

Figura 14 - Mapa de contorno da elevação topográfica do topo do leito argiloso no interior dos limites do depósito (eqüidistância das curvas de nível: $0,5 \mathrm{~m}$ )

*peso específico $=2 \mathrm{t} / \mathrm{m}^{3}$

200 REM: R. Esc. Minas, Ouro Preto, 55(3): 193-201, jul. set. 2002 
téril/minério aprimora as tomadas de decisões em estudos de exequiibilidade econômica, especialmente para depósitos de aproveitamento marginal.

\section{Agradecimentos}

Esse trabalho foi desenvolvido através do suporte financeiro do CNPq. Os autores são gratos aos engenheiros de minas Evandro dos Santos e Fernando Gambin pelo apoio computacional. Agradecimentos especiais vão para o grupo cerâmico Eliane (Cocal do Sul/SC), especialmente aos geólogos Márcio Geremias e Jorge Christ, que forneceram o banco de dados e permitiram a publicação desse artigo.

\section{Referências Bibliográficas}

ANNELS, A.E. Mineral deposits evaluation: a practical approach, UK: Chapman \& Hall, 1991. 436p.

BORTOLUZZI, C.A., AWDZIEJ, J., ZARDO, S.M. Geologia da Bacia do Paraná em Santa Catarina. In: Textos básicos de geologia e recursos minerais de Santa Catarina. Florianópolis: DNPM / Coordenadoria de Recursos Minerais da Secretaria da Ciência e Tecnologia, Minas e Energia, 1987. p.131-192.

COSTA, J.F. Developments in recoverable reserves and ore body modeling. WH Bryan Mining Geology Research Centre, The University of Queensland, 1997. 333p. (PhD Thesis)

CLARKE, K.C. Computation of the fractal dimension of topographic surfaces using the triangular prism surface area method. Computers \& Geosciences. Great Britain, v.12, n. 5, p.713-722, 1986.

DIMITRAKOPOULOS, R. Conditional simulation algorithms for modeling orebody uncertainty in open pit optimisation, International Journal of Surface, Reclamation and Environment, v.12, p.173-179, 1998.

GILBERT, L. E. Are topographic data sets fractal? Pageoph, USA, v. 131, n.1/2, p.241-254, 1989.

GOOVAERTS, P. Geostatistics for natural resources evaluation, Oxford University Press, 1997. 438p.

HERZFELD, U.C. ERIKSSON, M.G., HOLMLUND, P. On the influence of kriging parameters on the cartographic output - a study in mapping subglacial topography. Mathematical Geology, Sweeden, v.25, n. 7, p. 881-899, 1993.

ISAAKS, E.H. The application of Monte Carlo methods to the analysis of spatially correlated data. USA: Stanford University, 1990. 213p. (PhD Thesis)

ISAAKS, E.H., SRIVASTAVA, M.R. An introduction to applied geostatistics, New York: Oxford University Press, 1989. $561 \mathrm{p}$.

JOURNEL, A.J., ROSSI, M..E. When do we need a trend model in kriging?, Mathematical Geology. USA, v. 21, n. 7, p.715-739, 1989.

KRIGE, D.G., RENDU, J.M. The fitting of contour surfaces to hanging and footwall data for an irregular ore body, In: INTERNATIONAL SYMPOSIUM ON COMPUTER APPLICATIONS IN THE MINERAL INDUSTRIES (APCOM), 13. Proceedings... Clausthal, West Germany, 1975. p.C.V.1-12.

LUÍS J., SOARES, A., GONZAGA, J. SILVA, F. FERREIRA A. Geostatistical characterization the shape of an orebody by using mining and geological data, In: INTERNATIONAL SYMPOSIUM ON COMPUTER APPLICATIONS IN THE MINERAL INDUSTRIES (APCOM), 24. Proceedings... CIM published, Canada, 1994. p.402-409.

OLEA, R. A. Optimal contour mapping using universal kriging. Journal of Geophysical Research. USA, v. 79, n. 5, p.695-702, 1974.

OLIVEIRA, S.A., KOPPE, J.C., COSTA, J.F.C.L. Overburden volume estimation assisted by geostatistics in open cast coal mine, In: INTERNATIONAL SYMPOSIUM
ON COMPUTER APPLICATIONS IN THE MINERAL INDUSTRIES (APCOM), 25. Proceedings... Brisbane, p.181-187, 1995.

READING, H.G. Sedimentary environments and facies. Oxford: Blackwell Scientific Publications, 1986. 615p.

ROSSI, M. E. Simplifying the practice of kriging in presence of trends, In: INTERNATIONAL SYMPOSIUM ON COMPUTER APPLICATIONS IN THE MINERAL INDUSTRIES (APCOM), 21. Proceedings... USA, p.253-261, 1988.

ROSSI, M.E., ALVARADO C., S.B. Conditional simulations applied to recoverable reserves, In: INTERNATIONAL SYMPOSIUM ON COMPUTER APPLICATIONS IN THE MINERAL INDUSTRIES (APCOM), 27. Proceedings... London: United Kingdom, p.19-23, 1998.

ROSSI, M.E. Uncertainty and risk models for decision-making processes, In: INTERNATIONAL SYMPOSIUM ON COMPUTER APPLICATIONS IN THE MINERAL INDUSTRIES (APCOM), 28. Proceedings... Golden, U.S.A., p.185-195, 1999.

SCHMITT, M., BISQUAY, H. Structural description of digital elevation models. INTERNATIONAL GEOSTATISTICAL CONGRESS GEOSTATS 2000 (GEOSTATS 2000), 6. Proceedings (CD-ROM, T20)... Cape Town, South Africa, 2000. 9p.

STANGLER, R.L. Abordagem probabilística na avaliação de depósitos de argila cerâmica, Porto Alegre: PPGEM/UFRGS, 2001. 192p. (Dissertação de Mestrado).

STANGLER, R.L., COSTA, J.F.C.L., KOPPE, J.C. Risk in stripping ratio estimation, In: INTERNATIONAL SYMPOSIUM ON COMPUTER APPLICATIONS IN THE MINERAL INDUSTRIES (APCOM), 29. Proceedings... China: Beijing, p.81-86, 2001

THWAITES, A.M. Assessment of geological uncertainty for a mining project, In: INTERNATIONAL SYMPOSIUM ON COMPUTER APPLICATIONS IN THE MINERAL INDUSTRIES (APCOM), 27. Proceedings... London: United Kingdom, p.391-404, 1988.

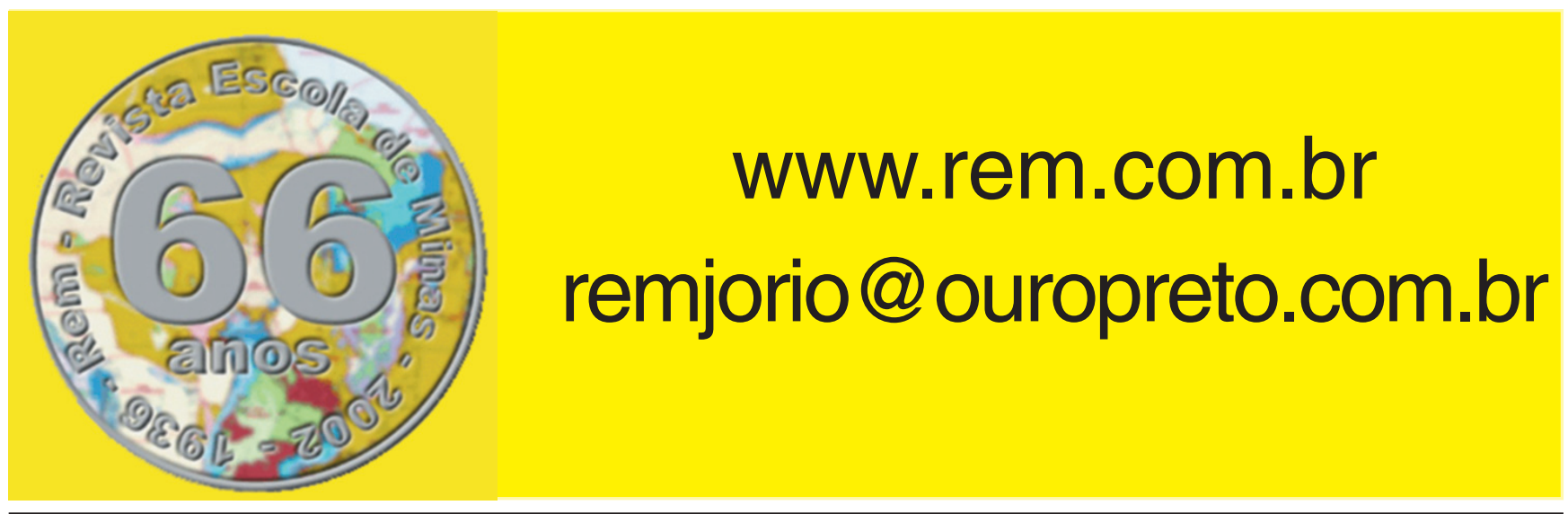

